\title{
РЕАКЦИОННАЯ СПОСОБНОСТЬ ПОЛИАРЕНОВ ПРИ ФОТООКИСЛИТЕЛЬНОЙ ДЕГРАДАЦИИ
}

\author{
(Представил М. Губергриц)
}

Облучение растворов полиаренов (ПА) в присутствии кислорода сопровождается генерированием синглетного кислорода $\left({ }^{1} \mathrm{O}_{2}\right)$, который может взаимодействовать с растворенными молекулами и обусловливать их окисление. Такой механизм характерен для фотоокисления (ФО) аценов, например для производных антрацена. Однако взаимодействием с ${ }^{1} \mathrm{O}_{2}$ трудно, а ряде случаев и невозможно, объяснить механизм фотоинициированного окисления многих других ПА, отличных по строению от аценов. В данном сообщении предпринята попытка выявить наиболее общие закономерности фотоокисления, свойственные широкому классу ПА.

\section{Методика эксперимента}

Для облучения растворов использовали монохроматическое УФ-излучение, выделенное с помощью интерференционных светофильтров из спектра излучения лампы ДКсШ-1000. Фотохимическое окисление ряда модельных ПА проводили в присутствии кислорода воздуха при температуре $20 \pm 1^{\circ} \mathrm{C}$ и постоянном перемешивании раствора. В качестве растворителей использовали воду и 95\%-ный этанол, причем для растворов в воде концентрация ПА не превышала предельной величины их истинной растворимости. Концентрацию арена в растворе обычно определяли спектрофотометрическим методом и только для бенз(а)пирена в воде - после его экстракции бензолом - с измерением флуоресценции методом Шпольского при $77 \mathrm{~K}$ в матрице бенз $(g, h, i)$ перилена в качестве внутреннего стандарта. Для измерения интенсивности УФ-облучения использовали ферриоксалатную актинометрическую систему. Квантовый выход ФО вычисляли по числу молекул ПА, подвергшихся ФО-деградации, отнесенному к количеству поглощенных углеводородом квантов света, на основе соответствующих кинетических зависимостей.

\section{Результаты}

Согласно ['], взаимодействие с ${ }^{1} \mathrm{O}_{2}$ для ряда ПА пиреновой структуры в полярных растворителях не может нести ответственности за их ФО. Это позволяет предположить, что наиболее вероятным путем окисления ПА пиреновой структуры является одноэлектронное окисление ПА в возбужденном состоянии. Для проверки этого предположения нами был поставлен эксперимент по ФО ряда аренов различной структуры в этаноле, как модельной органической жидкости, неплохо растворяющей ароматические углеводороды, и в воде, представляющей особый интерес 
как природный растворитель в аспекте проблем охраны окружающей среды.

Как видно из сопоставления квантовых выходов ФО аренов в использованных двух растворителях (табл. 1 и 2), эффективность процесса в воде для многих аренов оказывается более высокой, чем в этаноле. В ['] было показано, что скорость ФО бенз(а) пирена резко растет с увеличением доли воды в смеси этанол-вода. Это явление можно, очевидно, объяснить значительно повышенной диэлектрической проницаемостью воды $(80)$ в сравнении с показателем для $95 \%$-ного этанола $(24,6)$; повышение же диэлектрической проницаемости среды увеличивает вероятность протекания процесса переноса электрона, а тем самым и эффективность ФО. Проявление такой особенности воды как растворителя в известной степени подтверждает справедливость выдвинутого предположения.

Квантовые выходы (Ф) фотоокисления аренов в 95\%-ном этаноле

\begin{tabular}{|c|c|c|c|c|}
\hline Номер & Арен & $\begin{array}{c}\text { Длина вол- } \\
\text { ны облуче- } \\
\text { ния, нм }\end{array}$ & $\begin{array}{c}\text { Концентрация, } \\
\text { М/л }\end{array}$ & $\begin{array}{c}\Phi, \\
\text { молек./квант }\end{array}$ \\
\hline $\begin{array}{r}1 \\
2 \\
3 \\
4 \\
5 \\
6 \\
7 \\
\\
8 \\
9 \\
10 \\
11 \\
12\end{array}$ & $\begin{array}{l}\text { Бензол } \\
\text { Нафталин } \\
\text { Фенантрен } \\
\text { Хризен } \\
\text { Антрацен } \\
\text { Бенз(а)антрацен } \\
7,12 \text {-Диметил- } \\
\text {-бенз (а) антрацен } \\
\text { Бенз(а)пирен } \\
\text { Бенз(е)пирен } \\
\text { Перилен } \\
\text { Пирен } \\
\text { Коронен }\end{array}$ & $\begin{array}{l}256 \\
280 \\
280 \\
280 \\
280 \\
313 \\
\\
365 \\
365 \\
313 \\
405 \\
313 \\
313\end{array}$ & $\begin{array}{r}1,00 \cdot 10^{-4} \\
0,925 \cdot 10^{-4} \\
0,98 \cdot 10^{-4} \\
0,934 \cdot 10^{-4} \\
1,09 \cdot 10^{-4} \\
0,87 \cdot 10^{-4} \\
\\
0,90 \cdot 10^{-4} \\
0,81 \cdot 10^{-4} \\
1,07 \cdot 10^{-4} \\
0,92 \cdot 10^{-4} \\
1,04 \cdot 10^{-4} \\
0,76 \cdot 10^{-4}\end{array}$ & $\begin{array}{l}0,035 \pm 0,010 \\
(5,55 \pm 0,58) \cdot 10^{-4} \\
(6,61 \pm 0,40) \cdot 10^{-4} \\
(1,96 \pm 0,33) \cdot 10^{-4} \\
(1,25 \pm 0,05) \cdot 10^{-3} \\
(6,08 \pm 0,51) \cdot 10^{-4} \\
\\
0,0237 \pm 0,0012 \\
(9,15 \pm 0,47) \cdot 10^{-5} \\
(1,44 \pm 0,16) \cdot 10^{-4} \\
(2,85 \pm 0,20) \cdot 10^{-5} \\
(2,54 \pm 0,13) \cdot 10^{-4} \\
(6,07 \pm 0,33) \cdot 10^{-5}\end{array}$ \\
\hline
\end{tabular}

таблица 2

Квантовые выходы фотоокисления аренов в воде

\begin{tabular}{|c|c|c|c|c|}
\hline Номер & Арен & $\begin{array}{c}\text { Длина вол- } \\
\text { ны облуче- } \\
\text { ния, нм }\end{array}$ & $\begin{array}{c}\text { Концентрация, } \\
\text { М/л }\end{array}$ & $\begin{array}{c}\Phi, \\
\text { молек./квант }\end{array}$ \\
\hline $\begin{array}{l}1 \\
2 \\
3 \\
4 \\
5 \\
6 \\
7 \\
8 \\
\\
9\end{array}$ & $\begin{array}{l}\text { Бензол } \\
\text { Нафталин } \\
\text { Фенантрен } \\
\text { Бенз (a)пирен } \\
\text { Бенз (а)пирен * } \\
\text { Антрацен } \\
\text { Бенз(а) антрацен * } \\
7,12 \text {-Диметил- } \\
\text {-бенз(а)антрацен } \\
\text { Пнрен }\end{array}$ & $\begin{array}{l}256 \\
313 \\
313 \\
365 \\
366 \\
365 \\
366 \\
\\
313 \\
313\end{array}$ & $\begin{array}{l}5,0 \cdot 10^{-7} \\
5,0 \cdot 10^{-7} \\
5,0 \cdot 10^{-7} \\
4,0 \cdot 10^{-10} \\
5,0 \cdot 10^{-8} \\
4,0 \cdot 10^{-7} \\
8,6 \cdot 10^{-8} \\
\\
2,0 \cdot 10^{-7} \\
5,0 \cdot 10^{-7}\end{array}$ & $\begin{array}{c}0,390 \pm 0,036 \\
0,060 \pm 0,006 \\
0,0312 \pm 0,0036 \\
(2,04 \pm 0,38) \cdot 10^{-3} \\
5,4 \cdot 10^{-4} \\
(3,11 \pm 0,60) \cdot 10^{-3} \\
3,4 \cdot 10^{-3} \\
\\
0,184 \pm 0,002 \\
(3,98 \pm 0,38) \cdot 10^{-4}\end{array}$ \\
\hline
\end{tabular}

* Данные из [ $\left.{ }^{2}\right]$. 
Энергия стабилизации $(\Delta E)$ переходного состояния в реакции между ареном и синглетным кислородом и потенциалы одноэлектронного окисления арена в возбужденных состояниях

\begin{tabular}{|c|c|c|c|c|c|c|}
\hline Арен & $\begin{array}{c}E_{\text {вамо }}, \\
\beta \text {-ед. }\end{array}$ & $C_{a}$ & $C_{b}$ & $\begin{array}{c}\Delta E, \\
\beta-\text {-д. }\end{array}$ & $E_{o x} \underset{{ }^{\prime} \mathrm{B}}{ } E_{T}$ & $E_{0 x}-E_{\ni \mathrm{B}}$, \\
\hline $\begin{array}{l}\text { Бензол } \\
\text { Нафталин } \\
\text { Фенантрен } \\
\text { Хризен } \\
\text { Антрацен } \\
\text { Бенз(а) антрацен } \\
\text { 7,12-Диметил- } \\
\text {-бенз(а) антрацен } \\
\text { Бенз(а)пирен } \\
\text { Бенз(е) пирен } \\
\text { Перилен } \\
\text { Пирен } \\
\text { Коронен }\end{array}$ & $\begin{array}{l}1,000 \\
0,618 \\
0,605 \\
0,520 \\
0,414 \\
0,452 \\
\\
0,339 \\
0,371 \\
0,497 \\
0,347 \\
0,445 \\
0,539\end{array}$ & $\begin{array}{l}-0,577(1) \\
-0,425(1) \\
-0,232(1) \\
-0,296(1) \\
-0,440(9) \\
-0,445(7) \\
-0,459(7) \\
-0,268(7) \\
-0,084(9) \\
-0,289(1) \\
-\end{array}$ & $\begin{array}{c}0,577(4) \\
0,425(4) \\
0,340(4) \\
0,241(4) \\
0,440(10) \\
0,393(12) \\
\\
0,429(12) \\
0,175(10) \\
-0,084(12) \\
0,289(12) \\
-\end{array}$ & $\begin{array}{l}0,133 \\
0,131 \\
0,066 \\
0,072 \\
0,216 \\
0,182 \\
\\
0,264 \\
0,085 \\
0,000 \\
0,142 \\
- \\
-\end{array}$ & $\begin{array}{l}-1,350 \\
-1,086 \\
-1,178 \\
-1,105 \\
-0,754 \\
-0,866 \\
\\
-0,960 \\
-0,879 \\
-1,040 \\
-0,684 \\
-0,938 \\
-1,131\end{array}$ & $\begin{array}{l}-2,379 \\
-2,379 \\
-2,048 \\
-2,091 \\
-2,156 \\
-2,019 \\
-2,000 \\
-2,135 \\
-2,024 \\
-1,924 \\
-2,173 \\
-1,642\end{array}$ \\
\hline
\end{tabular}

Обозначения. $E_{\text {намо }}-$ энергия высшей занятой молекулярной орбитали; $C_{a}$ и $C_{b}-$ коэффициенты атомных орбиталей углеводородов $a$ и $b$ соответственно для высшей занятой молекулярной орбитали. В скобках стоит номер атома углерода по правилам JUPAC. Данные для $E_{T}$ и $E_{s}$ взяты из $\left[{ }^{3,4}\right]$, для $E_{o x}$ в ацетонитриле - из [5].

Наиболее вероятным акцептором электрона в рассматриваемой фотохимической системе является растворенный молекулярный кислород в основном состоянии; участие же возбужденных состояний кислорода в этом качестве можно не учитывать из-за малого времени их жизни в указанных растворителях. Остается открытым вопрос о природе возбужденного состояния исследуемого ПА. Для ПА в разбавленных растворах, использованных в данных опытах, наиболее вероятными состояниями являются низшие возбужденное-синглетное и триплетное. Критерием выбора между этими возбужденными состояниями могла служить наилучшая корреляционная зависимость между логарифмом квантового выхода ФО аренов и их электронодонорной способностью в возбужденных состояниях, характеризующихся величиной полярографического потенциала окисления основного состояния арена $\left(E_{o x}\right)$ за вычетом энергии возбуждения арена либо в триплетное $\left(E_{T}\right)$, либо в возбужденно-синглетное $\left(E_{s}\right)$ состояние (см. табл. 3). В корреляцию не были включены линейные ацены, в данном случае производные антрацена, которые легко окисляются по реакции с ${ }^{1} \mathrm{O}_{2}$.

Из анализа корреляционных уравнений (1) и (2), описывающих ФО в воде аренов $1-5$ и 9 (табл. 2), вытекает, что наиболее вероятным состоянием, ответственным за перенос электрона, следует счнтать триплетное, поскольку вклад переменной $\left(E_{o x}-E_{T}\right)$ в ретрессию более значителен $(\alpha=0,008)$, чем переменной $\left(E_{o x}-E_{s}\right)(\alpha=0,27)$ :

$$
\begin{aligned}
\ln \Phi & =-(19,2 \pm 3,0)-(13,7 \pm 2,8) \cdot\left(E_{o x}-E_{T}\right), \\
r & =0,924, s=1,199, n=6 ; \\
\ln \left(\Phi / t_{f}\right) & =-(38,2 \pm 22,8)-(13,1 \pm 10,3) \cdot\left(E_{o x}-E_{s}\right), \\
r & =0,537, s=3,197, n=6 .
\end{aligned}
$$

В уравнении (2) учитывается также время жизни флуоресцентного состояния ПА $\left(t_{j}\right)-31,49,63,105$ и 475 нс для бензола, бенз(а) пирена, 
фенантрена, нафталина и пирена []] соответственно, так как с реакцией одноэлектронного окисления возбужденно-синглетного состояния конкурирует весьма эффективная для этих аренов флуоресценция.

Таким образом, лимитирующей стадией ФО аренов, медленно реагирующих с ${ }^{1} \mathrm{O}_{2}$, можно считать образование катион-радикала арена в результате переноса электрона с триплета углеводорода на кислород. В общем же случае ФО аренов в разбавленных растворах можно представить схемой:

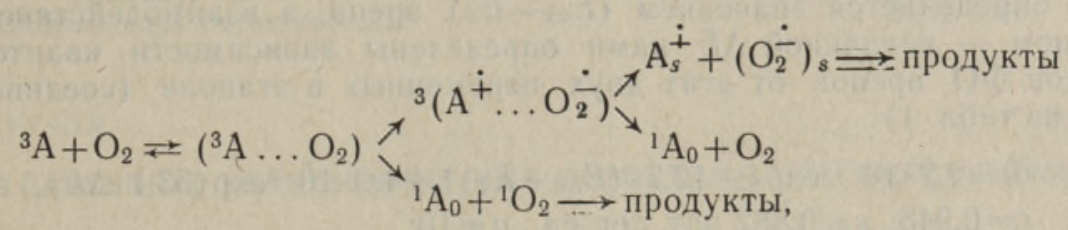

где ${ }^{3} \mathrm{~A}$ - молекула арена в триплетном состоянии, $\left({ }^{3} \mathrm{~A} \ldots \mathrm{O}_{2}\right)-$ комплекс столкновения, ${ }^{3}\left(\mathrm{~A}^{+} \ldots \mathrm{O}_{2}^{\dot{\bar{\sigma}}}\right)_{s}-$ сольватно-разделенная ион-радикальная пара, $\mathrm{A}_{s}^{\dot{+}}$ и $\left(\mathrm{O}_{2}^{\dot{-}}\right)_{s}-$ сольватированные катион- и анион-радикалы арена и кислорода соответственно.

Как следует из предложенной схемы, ФО аренов протекает по двум параллельным путям: в результате одноэлектронного окисления триплетного состояния ПА и в результате взаимодействия молекул с ${ }^{1} \mathrm{O}_{2}$. Очевидно, что учет обеих стадий позволит лучше описывать реакционную способность широкого ряда ПА в суммарном процессе фотоокислительной деградации, чем каждая из них в отдельности. Однако величины констант скоростей взаимодействия ПА с ${ }^{1} \mathrm{O}_{2}$ достоверно известны только для соединений антраценового ряда, а их экспериментальное определение, в частности для соединений пиренового ряда, оказалось недостаточно надежным [']. Поэтому реакционная способность ПА в случае $(4 \Pi+2 \Pi)$-циклоприсоединения ${ }^{1} \mathrm{O}_{2}$ была оценена нами исходя из теоретических соображений. Относительной мерой энергии активации этой реакции может служить величина энергии стабилизации активированного комплекса, которая определяется межмолекулярной энергией возмущения и которую можно оценить полуэмпирическим расчетом, например известным методом Хюккеля. Согласно теоретической модели [7], величина энергии возмущения второго порядка $(\Delta E)$ реакции, контролируемой обменным взаимодействием $(4 \Pi+2 \Pi)$, при перекрывании между терминальными П-орбиталями атомов $a, b$ углеводорода и атомов $c, d$ диенофильного ${ }^{1} \mathrm{O}_{2}$ в состоянии ${ }^{1} \Delta_{g}$ (см. рисунок), определяется выражением

$$
\Delta E=E_{\text {нсмо }}-E_{\text {взмо }}+\sqrt{\left(E_{\text {взмо }}-E_{\text {нсмо }}\right)^{2}+4\left(C_{a} / \sqrt{2}-C_{b} / \sqrt{2}\right)^{2} \beta_{\text {со }}^{2}},
$$

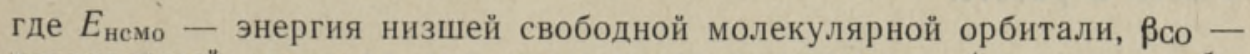
резонансный интеграл для пары углерод-кислород (остальные обозначения приведены в табл. 3$)$; принимается, что $E_{\text {нсмо }}=0,22 \beta$, $\beta_{\mathrm{CO}}=-0,29 \beta\left[{ }^{7}\right]$.

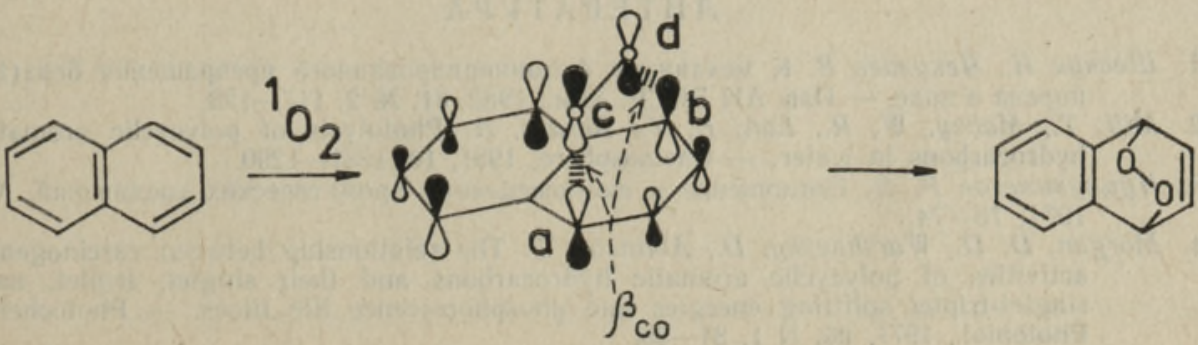


Значения $E_{\text {взмо, }} C_{a}$ и $C_{b}$ были вычислены в приближении ЛКАО-МО согласно теории Хюккеля с использованием в случае $\mathrm{CH}_{3}$-заместителя вспомогательного индуктивного параметра $-0,3 \beta\left[{ }^{8}\right]$. Рассчитанные значения величин $\Delta E$, характеризующие способность ${ }^{1} \mathrm{O}_{2}$ к циклоприсоединению в наиболее реакционноспособных положениях аренов, приведены в табл. 3.

Исходя из предложенной схемы (3) фотоинициированного окисления и соображения, что выход ион-радикалов в процессе фотопереноса электрона определяется значением $\left(E_{o x}-E_{T}\right)$ арена, а взаимодействие ${ }^{1} \mathrm{O}_{2}$ с ареном - величиной $\Delta E$, нами определены зависимости квантовых выходов $Ф О$ аренов от этих двух переменных в этаноле (соединения $1-10$ из табл. 1$)$ :

$$
\begin{aligned}
& \Phi=4,2 \cdot 10^{-10} \exp \left(-12,7 \cdot\left(E_{\text {ox }}-E_{T}\right)\right)+1,9 \cdot 10^{-8} \exp (53,1 \cdot \Delta E), \\
& r=0,948, \quad s=0,882 \text { нат. лог. ед., } n=10 ;
\end{aligned}
$$

и в воде (соединения $1-8$ из табл. 2 ):

$$
\begin{aligned}
& \Phi=6,1 \cdot 10^{-8} \exp \left(-11,7 \cdot\left(E_{\text {ox }}-E_{T}\right)\right)+5,9 \cdot 10^{-11} \exp (82,5 \cdot \Delta E), \\
& r=0,948, s=0,941 \text { нат. лог. ед., } n=8 .
\end{aligned}
$$

Надо заметить, что в описанных выше корреляционных зависимостях мы не учитывали квантовый выход триплетного состояния ПА, так как его значение для многих ПА при комнатной температуре и при наличии в растворе кислорода приближается к единице [].

Полученные на основе уравнений (5) и (6) данные достаточно хорошо согласуются с экспериментальными значениями квантовых выходов ФО аренов. Это обстоятельство дает основание подчеркнуть настоятельную необходимость учета обоих, параллельно протекающих процессов взаимодействия углеводорода $\mathrm{c}^{1} \mathrm{O}_{2}$ и одноэлектронного окисления триплетного состояния арена в изученном процессе и позволяет предсказать реакционную способность ПА в этаноле и воде, т. е. позволяет приблизиться к созданию модели фотоинициированной деградации ПА в окружающей среде.

В заключение укажем, что вклад каждой из указанных важнейших составляющих в суммарную величину реакционной способности ПА в процессе их фотохимического окисления в конечном счете определяется специфическими особенностями их молекулярной структуры. В тех случаях, когда строение молекулы не позволяет ей эффективно реагировать c ${ }^{1} \mathrm{O}_{2}$, от реакции межмолекулярного переноса электрона с триплета углеводорода на кислород зависит весь путь фотохимического окисления.

Автор выражает благодарность $M$. Губергрицу за помощь и ценные советы в работе.

\section{Л И ТЕ РА Т Y PA}

1. Шевчук И., Чекулаев В. К механизму фотоинициированного превращения бенз(а). пирена в воде. - Изв. АН ЭССР. Хим., 1982, 31, № 2, 117-123.

2. Mill, T., Mabey, W. R., Lan, B. Y., Baraze, A. Photolysis of polycyclic aromatic hydrocarbons in water. - Chemosphere, 1981, 10, 1281-1290.

3. Нурмухаметов P. Н. Поглощение и люминесценция ароматических соединений. М., $1971,70-74$.

4. Morgan, D. D., Warshavsky, D., Atkinson, T. The relationship between carcinogenic activities of polycyclic aromatic hydrocarbons and their singlet, triplet, and singlet-triplet splitting energies and phosphorescence life times. - Photochem. Photobiol., 1977, 25, N 1, 31-38. 
5. Pysh, E. S., Yang, N. C. Polarographic oxidation potentials of aromatic compounds. - J. Amer. Chem. Soc., 1963, 85, N 14, 2124-2130.

6. Birks, J. B. Photophysics of Aromatic Molecules. London, 1970, 126.

7. Heuvel, C. J. M., Verhoeven, J. W. P., Boer, T. J. A frontier orbital description of the reaction of singlet oxygen with simple aromatic system. - Rec. trav. chim., 1980, 99, N 9, 280-284.

8. Стрейтвизер Э. Теория молекулярных орбиталей для химиков-органиков. М., 1965.

9. Birks, J. B. Organic Molecular Photophysics, 2. London-New York-Sydney, $1975,118$.

Институт химии

Академии наук Эстонской ССР
Поступила в редакцию $24 / \mathrm{X} 1985$

\section{SEVTSUK}

\section{POLOAREENIDE REAKTSIOONIVOIME FOTOKEEMILISEL OKSUDEERIMISEL}

Töös on määratud rea polüareenide fotooksüdatsiooni kvantsaagised vee ja etanooli lahustes. Saadud andmete interpreteerimiseks on välja pakutud mehhanism, mis koosneb kahest paralleelselt kulgevast reaktsioonist: polüareeni triplettoleku üheelektroniline oksüdatsioon ja süsivesiniku ühinemisreaktsioon singletse hapnikuga. Môlema protsessi osakaal polüareeni fotooksüdatsioonis sõltub suuresti molekuli struktuurist.

\section{SHEVCHUK}

\section{REACTIVITY OF POLYARENES IN THE PHOTOOXIDATION}

The author presents a report on the photooxidation quantum yield of a number of polyarenes in water and in ethanol solvents. The mechanism of photooxidation may occur in two parallel ways: one-electron oxidation triplet state of polyarenes and reaction singlet oxygen with hydrocarbons. 